\title{
Price estimation for miscibility gap alloy thermal storage systems ${ }^{\star}$
}

\author{
Alexander Post*, Anthony Rawson, Heber Sugo, Dylan Cuskelly, Mark Copus, James Bradley, and Erich Kisi \\ University of Newcastle, Callaghan, NSW, Australia
}

Received: 30 January 2017 / Received in final form: 10 July 2017 / Accepted: 27 July 2017

\begin{abstract}
Miscibility gap alloys (MGAs) are an emerging thermal energy storage material with unique thermal properties that may be of particular interest to the renewable energy industry. In this study, they are compared to state of the art thermal storage technologies on an economic basis, with consideration given to material prices, manufacturing costs, specific deployment infrastructure costs, maintenance schedule cost and the potential for material salvage. Cost estimates are provided for seven different MGAs deployed in three different thermal storage implementations.
\end{abstract}

\section{Introduction}

The development of cost effective energy storage methods is a major hurdle in the global transition to renewable energy technology, as large scale renewable sources rarely output a steady supply of power. Current energy storage technologies often suffer from high cost due to expensive materials, limited cycle lifetimes, and poor energy density. For this reason, storing energy thermally is emerging as one of the most favourable large scale storage alternatives, thanks to the use of low cost materials and long cycle lifetimes opposed to batteries [1].

When designing a thermal energy storage (TES) system, the energy density of the storage material dictates the required volume of material for a given storage capacity. The thermal conductivity dictates design of the heat exchange interface, with a high thermal conductivity decreasing the necessary heat exchange surface area. The ideal TES medium can then be characterized by low material cost, high energy density and thermal conductivity, with suitable operating temperature and phase transition temperature, if a phase change material (PCM) is being utilized.

Costing and thermal performance data on a wide variety of sensible and latent thermal storage media have been reviewed in recent years [1-4]. However, the cost of infrastructure is often neglected in these analyses, despite accounting for between $50 \%$ and $70 \%$ of the total capital cost of TES systems [4-7]. Although it is typically assumed

\footnotetext{
` Paper presented at: World Renewable Energy Congress XVI, 5-9 February 2017, Murdoch University, Western Australia.

* e-mail: alexander.post@uon.edu.au
}

to be constant for a given storage method (e.g. two tank molten, thermocline, etc.), the cost of infrastructure can vary considerably based on storage media thermal properties. A review study by Liu et al. in 2016 [8] features the complete capital costs including infrastructure of a range of TES technologies, and places the cost of storage between 19.74 and $48.48 \$ / \mathrm{kWh}_{\mathrm{t}}$ for currently applied large scale technologies operating over temperature differences of $300^{\circ} \mathrm{C}$. The data presented by Liu et al. has been used as a benchmark for the current state of the art. In the present study, total capital costs for several novel TES system arrangements have been considered, with storage over the same temperature difference, resulting in overall estimates of cost in $\$ / \mathrm{kWh}_{\mathrm{t}}$ compared to those published by Liu et al.

Here we perform an economic analysis of the miscibility gap alloy (MGA) method of TES. This new storage technology, described in detail in [9-11], involves the utilization of material pairs consisting of a high melting point matrix encapsulating grains of an immiscible low melting point metal. The matrix rapidly distributes thermal energy through the encapsulated constituent, which undergoes a phase change storing a large amount of energy as latent heat of fusion. Both matrix and included phase provide additional storage as sensible heat. The result is a storage system that exhibits the high energy density of latent heat storage systems, without the need for the excessive heat exchanger infrastructure necessary to disperse heat through a low thermal conductivity solid phase.

The operating temperature range of an MGA should encompass the melting temperature of the encapsulated phase to make use of latent heat storage, and ranges considerably from $232^{\circ} \mathrm{C}(\mathrm{Sn})$ to $1414^{\circ} \mathrm{C}$ ( $\mathrm{Si}$ ) for the MGAs considered in this study. In all cases, sensible heat storage is 
Table 1. Material cost bounds used in economic analysis.

\begin{tabular}{lccl}
\hline Material & Cost lower bound (US\$ $/ \mathrm{T})$ & Cost upper bound (US\$/T) & References \\
\hline $\mathrm{Al}$ & 2400 & 5000 & {$[16-18]$} \\
$\mathrm{Brass}$ & 3000 & 28000 & Assumed (over Zn and Cu range) \\
$\mathrm{Cu}$ & 5000 & 27000 & {$[19-21]$} \\
$\mathrm{C}$ & 320 & 850 & {$[22-25]$} \\
$\mathrm{Fe}$ & 400 & 1000 & {$[26-28]$} \\
$\mathrm{Mg}$ & 3000 & 6000 & {$[29-31]$} \\
$\mathrm{Si}$ & 1700 & 2500 & {$[32-34]$} \\
$\mathrm{SiC}$ & 820 & 2050 & {$[35-37]$} \\
$\mathrm{Sn}$ & 20000 & 45000 & {$[38-40]$} \\
$\mathrm{Zn}$ & 1500 & 3500 & {$[41-43]$} \\
\hline
\end{tabular}

also available over a wide temperature range outside of the phase transition temperature, with no lower bound, and an upper bound dictated by the lowest among: (a) the maximum service temperature of the matrix phase, (b) material solubility limits or (c) boiling temperature of the encapsulated phase. Calculations of the total combined sensible and latent heat storage capacity are calculated here as the latent heat of the melting phase, and a $150{ }^{\circ} \mathrm{C}$ temperature difference in stored sensible heat on either side of the phase transition temperature, in order to be comparable to the figures presented by Liu et al.

\section{Analysis method}

\subsection{TES deployments}

Three theoretical systems each suited to different scales and operating temperatures, have been examined in this study in order to estimate the total system cost. The first is a small scale system in which excess photovoltaic output is stored thermally through resistive heating of an MGA block, to be later re-captured by fan-blown air for space heating or low temperature industrial processes such as drying or curing, aimed at lower operating temperature $\left(<600^{\circ} \mathrm{C}\right)$ MGAs.

The second, described in the conference paper by Rawson et al. [12], is modelled after a conventional thermal storage system for power production, featuring a modular array of MGA filled $200 \mathrm{~L}$ barrels, with a single central heat transfer pipe taking advantage of the material's high thermal conductivity. Barrels are stored within an inert gas filled shipping container on concrete foundation. This implementation is suited to any MGAs with operating temperatures between 400 and $700^{\circ} \mathrm{C}$.

The final deployment, intended for use in a central tower concentrated solar power (CSP) plant [13], involving the replacement of the central receiver with a directly irradiated MGA thermal storage block. A beam-down modification is utilized allowing the storage block/receiver to be located at the base of the tower. This deployment suits moderate to the highest temperature MGAs $\left(>650^{\circ} \mathrm{C}\right)$, in line with the operating temperatures of typical large scale CSP plants.

\subsection{Cost modelling method}

Material costs have been calculated using cost estimates of the powder metallurgy techniques used to produce MGAs [14] described within [15], assumed to be of an economical batch size with consideration given to wasted material during manufacturing, tooling and equipment cost and lifetime. Other overheads including operator wages, energy and land rates are covered with a cost per time, converted into cost per unit by an estimated production rate. Infrastructure costs were evaluated on a per system basis. The categories of piping, encapsulation, insulation and atmosphere are accounted for with costs per unit length, area or volume respectively. These costs were normalised with respect to energy stored by dividing by the deployment volume and energy density. Salvage benefits were evaluated as a proportion of the material costs initially incurred (assuming that the commodity price of the materials will account for inflation after the design lifetime is complete) ranging between $6.25 \%$ for graphite matrix MGAs and $25 \%$ for the fully immiscible metal system, which can be recovered by simply melting both constituents.

All costs were added to yield an estimate of the total cost per $\mathrm{kWh}$ of thermal storage capacity. There is considerable variation in all the costs associated with the implementation of an MGA thermal storage system, it was thus felt prudent to present bounds on costs rather than a definite figure. The bounds in this case have been propagated through the calculations using a maximum possible error approach.

\subsection{Material cost estimates}

Cost estimates for materials, infrastructure and manufacturing were performed by analysing literature, catalogues and websites. At least three prices were obtained for each estimate to ensure that the raw materials were commercially available over the quoted price ranges. Considerable uncertainty exists in cost estimating without an actual project occurring, thus the bounds for each cost were intentionally left broad. Table 1 summarises the price bounds utilized in the economic analysis with reference. 
Table 2. Recommended infrastructure elements and price bounds for MGA deployments.

\begin{tabular}{|c|c|c|c|c|c|c|c|c|c|c|}
\hline \multirow{2}{*}{$\frac{\text { MGA }}{\text { Brass-C }}$} & \multicolumn{2}{|c|}{ Atmosphere } & \multicolumn{2}{|l|}{ Piping } & \multicolumn{2}{|c|}{ Encapsulation } & \multicolumn{2}{|l|}{ Encapsulation $^{\mathrm{a}}$} & \multicolumn{2}{|l|}{ Insulation } \\
\hline & Argon & & SS pipe & & SS sheet & & SS barrel & & $\begin{array}{l}\text { High temp min } \\
\text { wool }\end{array}$ & \\
\hline & 0.8 & 1.2 & 24 & 36 & 132 & 198 & 292 & 356 & 10 & 15 \\
\hline $\mathrm{Cu}-\mathrm{C}$ & Argon & & SS pipe & & SS sheet & & SS barrel & & $\begin{array}{l}\text { High temp min } \\
\text { wool }\end{array}$ & \\
\hline & 0.8 & 1.2 & 24 & 36 & 132 & 198 & 292 & 356 & 10 & 15 \\
\hline $\mathrm{Cu}-\mathrm{Fe}$ & Argon & & SS pipe & & SS sheet & & SS barrel & & $\begin{array}{l}\text { High temp min } \\
\text { wool }\end{array}$ & \\
\hline & 0.8 & 1.2 & 24 & 36 & 132 & 198 & 292 & 356 & 10 & 15 \\
\hline $\mathrm{Mg}-\mathrm{Fe}$ & Air & & MS pipe & & MS sheet & & Barrel & & Min wool & \\
\hline & 0 & 0 & 12 & 18 & 32 & 48 & 225 & 277 & 4 & 6 \\
\hline $\mathrm{Si}-\mathrm{SiC}$ & Argon & & Ceramic pipe & & $\begin{array}{l}\text { Ceramic } \\
\text { coating }\end{array}$ & & $\begin{array}{l}\text { Ceramic coated } \\
\text { barrel }\end{array}$ & & $\begin{array}{l}\text { High temp min } \\
\text { wool }\end{array}$ & \\
\hline & 0.8 & 1.2 & 48 & 72 & 264 & 396 & 850 & 1042 & 10 & 15 \\
\hline $\mathrm{Sn}-\mathrm{Al}$ & Air & & MS pipe & & MS sheet & & Barrel & & Min wool & \\
\hline & 0 & 0 & 12 & 18 & 32 & 48 & 225 & 277 & 4 & 6 \\
\hline $\mathrm{Zn}-\mathrm{C}$ & Air & & MS pipe & & MS sheet & & Barrel & & Min wool & \\
\hline & 0 & 0 & 12 & 18 & 32 & 48 & 225 & 277 & 4 & 6 \\
\hline
\end{tabular}

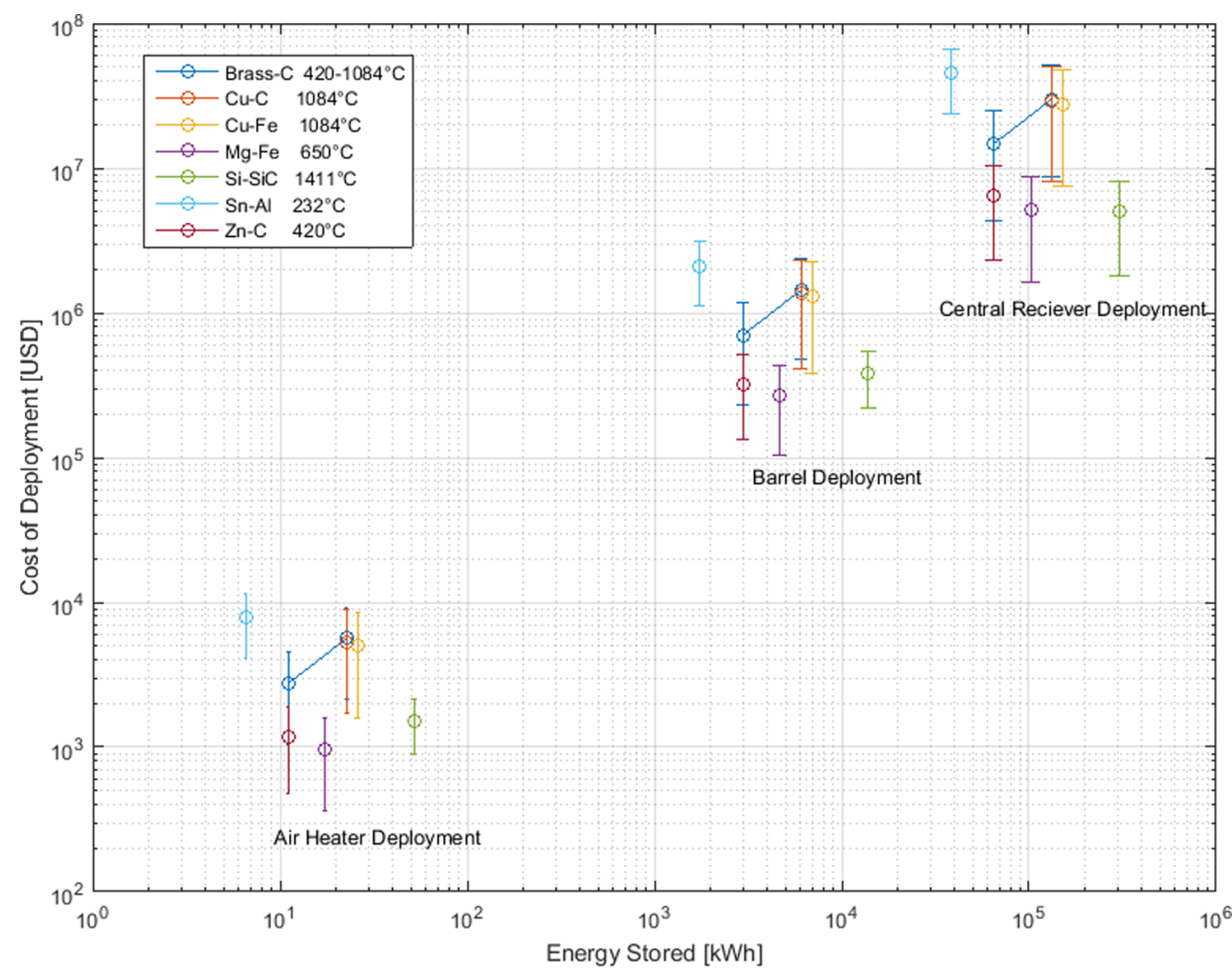

Fig. 1. Total estimated cost of deployment plotted against stored energy for seven different miscibility gap alloys in three different deployments. 


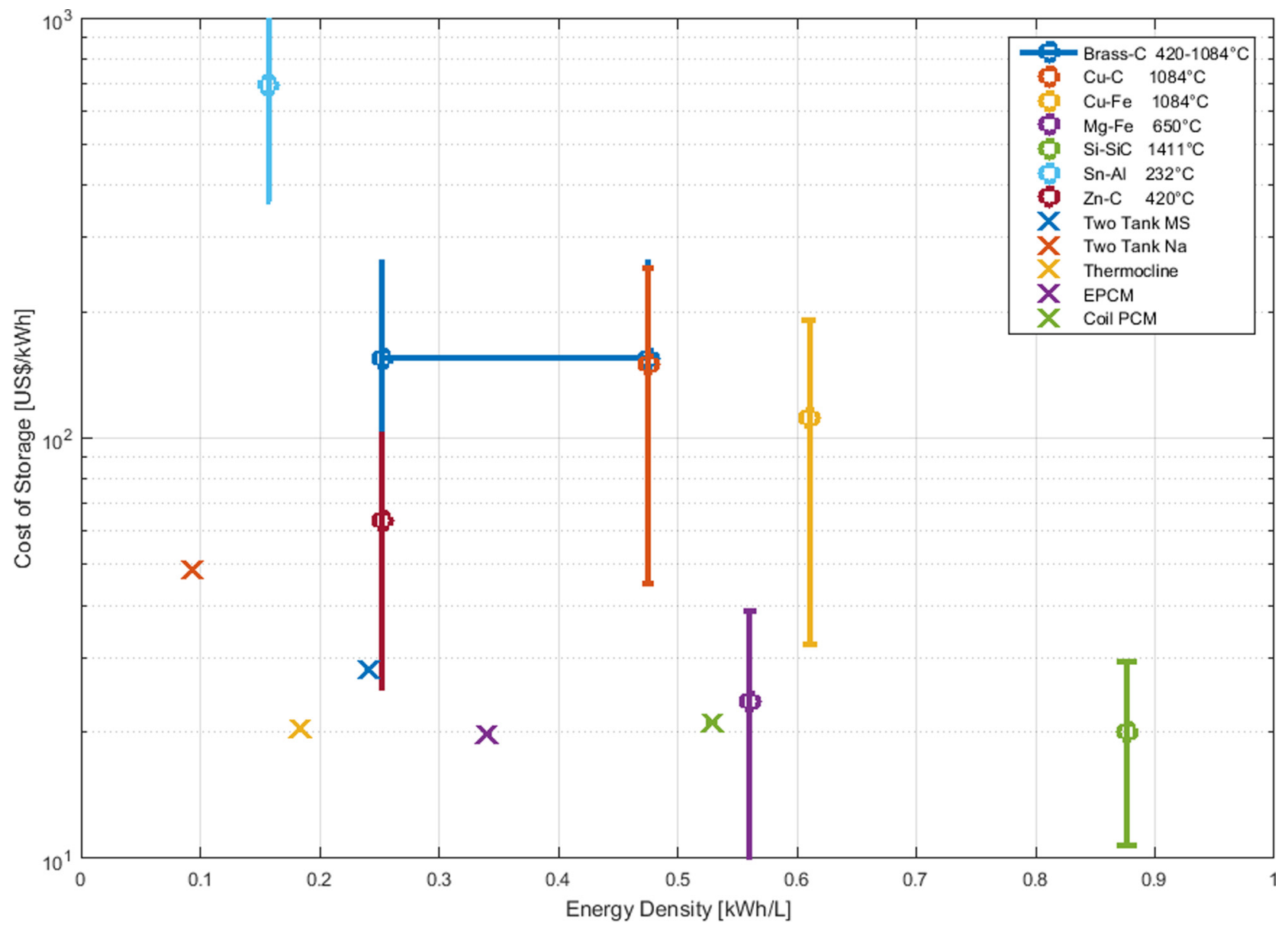

Fig. 2. Mean cost per unit energy of storage over the three different deployments for the seven different miscibility gap alloys, compared to state of the art thermal storage systems summarised in Table 3.

\subsection{Infrastructure costs}

Infrastructure costs depend on both the particular deployment and the MGA utilized, primarily as a result of variations in operating temperature and capacity for oxidation of the matrix material. The recommended infrastructure elements for each MGA analysed in this article are shown in Table 2.

Infrastructure prices were sourced from a number of different resources; heat exchanger piping was costed from [44] with assumptions made for stainless steel and ceramic equivalents. Encapsulation costs were taken from [45], ceramic coating cost was assumed. Barrel prices were found from [46], whilst shipping container costs were based on $[47,48]$ with an assumption on retrofitting cost. The foundation slab was assumed to be rectangular $7 \times 3 \mathrm{~m}$ in dimension and a depth of $1 \mathrm{~m}$. Concrete with reinforcement was considered to cost $620\left(\mathrm{US} \$ / \mathrm{m}^{3}\right)$. Insulation prices were taken from [49]. An uncertainty of $20 \%$ was assumed for all costs.

\section{Results}

Figure 1 contains plots of the overall cost of storage systems in US\$ against the energy storage capacity in $\mathrm{kWh}$, for each of the proposed MGA systems, in each of the three deployments mentioned in Section 2.1. Plotted points represent the mean cost, with upper and lower bounds on error margins.

It can be observed from Figure 1 that the cost of deployment is approximately proportional to energy storage capacity across the three deployments considered. Thus to provide an overall costing figure independent of system size, the total cost of deployment can be normalised against energy stored for each deployment, and the resulting figures averaged. This data is portrayed in Figure 2, in which the capacity-normalised cost of storage averaged across all three deployments is plotted against energy density, in the same manner as Figure 1.

As mentioned in Section 1, an ideal TES medium can be characterized by high energy density and low cost, which in the case of Figure 2 occurs in the lower right corner of the plot. In this case, the capital cost of several MGA thermal storage methods are competitive with mature TES systems, particularly $\mathrm{Mg}-\mathrm{Fe}$ and $\mathrm{Si}-\mathrm{SiC}$. In terms of energy density, with the exclusion of the $\mathrm{Sn}-\mathrm{Al}$ system, no MGAs are exceeded by state of the art sensible heat systems, and only the two state of the art PCM systems approximate the typical MGA energy density.

In terms of cost breakdown, costs involved in implementing a MGA thermal storage solution approximated in this study are dissimilar to molten salt 
(a)

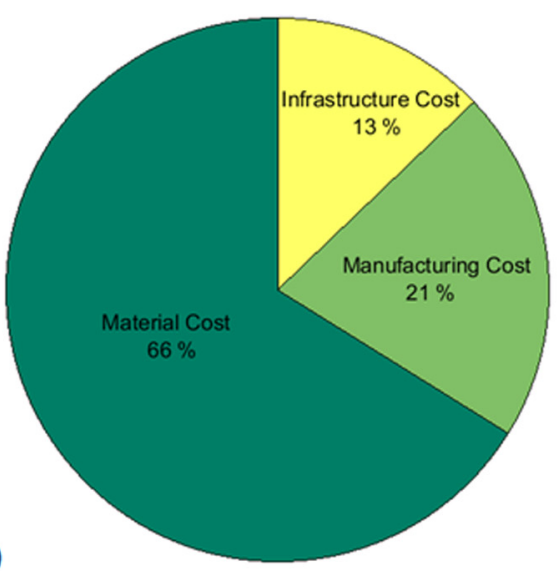

(b)

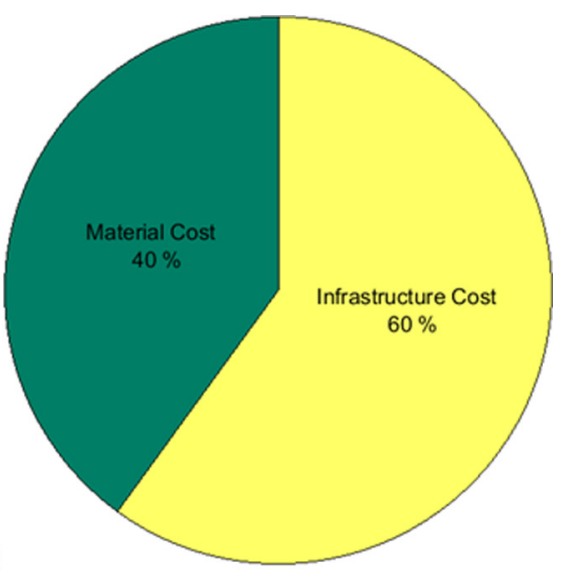

Fig. 3. Comparison of the typical cost breakdown for a MGA (a) and molten salt (b) thermal storage deployments.

Table 3. Cost and energy density of state of the art TES systems.

\begin{tabular}{|c|c|c|c|c|}
\hline System & $\begin{array}{l}\text { Storage } \\
\text { method }\end{array}$ & $\begin{array}{l}\text { Capital } \\
\text { cost } \\
\left(\mathrm{US} \$ / \mathrm{kWh}_{\mathrm{t}}\right)\end{array}$ & $\begin{array}{l}\text { Volumetric energy } \\
\text { density }\left(\mathrm{kWh}_{\mathrm{t}} / \mathrm{m}^{3}\right)\end{array}$ & $\begin{array}{l}\text { Relevant } \\
\text { references }\end{array}$ \\
\hline $\begin{array}{l}\text { Two-tank molten salt } \\
\text { (Hitec XL) }\end{array}$ & Sensible & 28.21 & 240.2 & {$[8,50]$} \\
\hline Two-tank liquid sodium & Sensible & 48.48 & 92.9 & {$[8,51]$} \\
\hline Thermocline quartz/sand & Sensible & 20.26 & 183.3 & {$[8]$} \\
\hline $\begin{array}{l}\mathrm{EPCM}^{\mathrm{a}} \text { chloride salt } \\
\text { (alumina shell) }\end{array}$ & Latent & 19.74 & 340.6 & {$[8,52,53]$} \\
\hline $\begin{array}{l}\text { Coil in tank carbonate salt } \\
\text { (stainless tubing) }\end{array}$ & Latent & 21 & 529.0 & {$[8,54]$} \\
\hline
\end{tabular}

${ }^{a}$ Encapsulated phase change material.

implementations and to the general state of the art. MGA system costs are dominated by material and manufacturing costs $(\sim 50-90 \%)$ when compared to salts $(30-50 \%)$. Figure 3 illustrates this by depicting the cost breakdown of a typical MGA storage system developed in this report to that of a typical molten salt system.

It should be noted the ongoing operation and maintenance costs have been excluded from both this analysis and the present literature. This can be important when calculating the LCOE of a power plant as the operating and maintenance costs constitute a substantial fraction of the lifetime cost of the plant. In this regard, maintenance for a MGA thermal storage system is thought to be very minor, involving recharging of the inert atmosphere to keep the exterior free of oxidation. Operating costs can also be considered minor due to the high thermal conductivity of MGAs mitigating the need for major pumping infrastructure and the resulting parasitic losses. The design life of an MGA storage system is also estimated to exceed 20 years of daily thermal cycling - the materials and infrastructure are not damaged by sub-cooling and are unlikely to ever experience localised over-heating due to their very high thermal diffusivity. For MGA deployments on-going costs should not be a significant factor in LCOE calculations, especially in comparison to current alternatives.
It should also be noted that the temperature range used in this study of $300^{\circ} \mathrm{C}$ is large for a thermal storage system supplying heat to a power cycle, and was selected in order to provide consistent comparison with other systems presented in literature. A key advantage of MGA and other PCM storage is the ability to operate over a narrow temperature range - as the temperature range used for sensible heat storage decreases, so too does energy density, but to a much lesser extent for PCM storage media than for those using purely sensible heat storage. In the case of a TES used to supply heat to a power cycle, a constant supply temperature is extremely favourable, and carries its own financial benefits through increased power cycle efficiency.

\section{Conclusion}

A thorough economic analysis of MGAs as thermal storage media has been performed, with consideration given to material, manufacturing, infrastructure and maintenance costs as well as potential salvage benefits. MGAs where shown to be cost-competitive with current TES methods in terms of US $\$ / \mathrm{kWh}_{\mathrm{t}}$ of storage, while having the ability to operate over a significantly larger range of temperatures. It 
can be summarised that MGA thermal performance is typified by high energy densities and thermal conductivity when compared to conventional TES methods, while economic performance can be typified by high material costs and low infrastructure costs, resulting in an overall system cost similar to that of state of the art systems.

\section{References}

1. T. Kousksou, P. Bruel, A. Jamil, T. El Rhafiki, Y. Zeraouli, Energy storage: applications and challenges, Sol. Energy Mater. Sol. Cells 120, 59 (2014)

2. G. Alva, L. Liu, X. Huang, G. Fang, Thermal energy storage materials and systems for solar energy applications, Renew. Sustain. Energy Rev. 68, 693 (2017)

3. A. Gil, M. Medrano, I. Martorell, A. Lázaro, P. Dolado, B. Zalba, L.F. Cabeza, State of the art on high temperature thermal energy storage for power generation. Part 1 concepts, materials and modellization, Renew. Sustain. Energy Rev. 14, 31 (2010)

4. S. Kuravi, J. Trahan, D.Y. Goswami, M.M. Rahman, E.K. Stefanakos, Thermal energy storage technologies and systems for concentrating solar power plants, Prog. Energy Combust. Sci. 39, 285 (2013)

5. IRENA, Renewable energy technologies cost analysis series: concentrating solar power, Compr. Renew. Energy 3, 595 (2012)

6. C. Smith, Y. Sun, B. Webby, A. Beath, F. Bruno, Cost analysis of high temperature thermal energy storage for solar power plant, in Solar 2014, Melbourne, Australia (2014)

7. W. Zhang, Concentrating Solar Power - State of the Art, Cost Analysis and Pre-Feasibility Study for the Implementation in China (Institut für Energiewirtschaft und Rationelle Energieanwendung, Stuttgart, 2009)

8. M. Liu, N.H. Steven Tay, S. Bell, M. Belusko, R. Jacob, G. Will, W. Saman, F. Bruno, Review on concentrating solar power plants and new developments in high temperature thermal energy storage technologies, Renew. Sustain. Energy Rev. 53, 1411 (2016)

9. E. Kisi, H. Sugo, D. Cuskelly, T. Fiedler, A. Rawson, A. Post, J. Bradley, M. Copus, S. Reed, Miscibiliy gap alloys - a new thermal energy storage solution, in World Renewable Energy Congress 2017, Perth, Australia (2017)

10. A. Rawson, E. Kisi, H. Sugo, T. Fiedler, Effective conductivity of $\mathrm{Cu}-\mathrm{Fe}$ and $\mathrm{Sn}-\mathrm{Al}$ miscibility gap alloys, Int. J. Heat Mass Transf. 77, 395 (2014)

11. H. Sugo, E. Kisi, D. Cuskelly, Miscibility gap alloys with inverse microstructures and high thermal conductivity for high energy density thermal storage applications, Appl. Therm. Eng. 51, 1345 (2013)

12. A. Rawson, H. Sugo, E. Kisi, Characterising thermal properties of miscibility gap alloys for thermal storage applications, in Solar2014: The 52nd Annual Conference of the Australian Solar Council, Melbourne, Australia (2014)

13. Solúcar, Inabensa, Fichtner, Ciemat, DLR, Final Technical Progress Report: 10 MW Solar Thermal Power Plant for Southern Spain, 2005

14. M. Copus, S. Reed, E. Kisi, H. Sugo, J. Bradley, Scaling up miscibility gap alloy thermal storage materials, in WREC 2017, Perth, Australia (2017)

15. M.F. Ashby, Materials Selection in Mechanical Design (Butterworth-Heinemann, 2011)
16. HENGDA, Aluminium Metal Powder [WWW Document], 2015, Alibaba.com, URL: http://www.alibaba.com/prod uct-detail/Aluminum-Metal-Powder_316434621.html

17. KingStyle Metal, KingStyle Metal, China Factory Al 99\% Aluminium Metal Powder [WWW Document], 2015, Alibaba.com, URL: http://www.alibaba.com/product-detail/ china-factory-al-99-aluminum-metal_529924447.html

18. Vantaa, Aluminium Metal Powder [WWW Document], 2015, Alibaba.com, URL: http://www.alibaba.com/prod uct-detail/Aluminum-Metal-Powder 1607338165.html

19. Bosun, Copper Cut Wire Shot, $99 \overline{\%}$ [WWW Document], 2015, Alibaba.com, URL: http://www.alibaba.com/prod uct-detail/Copper-Cut-Wire-Shot-99-roundness_14205555 22.html? $\mathrm{s}=\mathrm{p}$

20. CDH857, Dendritic Electrolytic Copper Powder [WWW Document], 2014, Alibaba.com

21. CNPC, Copper Powder [WWW Document], 2015, Alibaba. com, URL: http://www.alibaba.com/product-detail/Cop per-Powder_728148346.html?s=p

22. A. Dashkov, Graphite: Time to Invest, or Flavor of the Day? [WWW Document], Credit Writedowns, 2012, URL: https://www.creditwritedowns.com/2012/04/graphite-inve sting.html

23. GRAPHITE 101, Graphite One Resources [WWW Document], 2014, URL: http://graphiteoneresources.com/inves tors/graphite_101/(accessed on: 2015/01/01)

24. Saint Jean Carbon, Graphite Prices [WWW Document], 2014, URL: http://www.saintjeancarbon.com/index.php/ graphite/prices/ (accessed on: 2015/01/01)

25. Talga Resources, About Graphite [WWW Document], 2014, URL: http://www.talgaresources.com/irm/content/aboutgraphite.aspx?RID $=332$ (accessed on: 2015/01/01)

26. CNPC, Iron Powder Price Ton [WWW Document], 2014, Alibaba.com, URL: http://www.alibaba.com/product-de tail/iron-powder-price-ton_1825594415.html?s=p

27. CNPC, Electrolytic Iron Metal Powder [WWW Document], 2014, Alibaba.com, URL: http://www.alibaba.com/productdetail/Electrolytic-iron-METAL-powder_2001088628.html

28. Xingyue, High Purity Competitive Reduced Iron Powder [WWW Document], 2015, Alibaba.com, URL: http://www. alibaba.com/product-detail/High-purity-competitive-reduc ed-iron-powder_60031676891.html

29. CNPC, Magnesium Powder Price [WWW Document], 2014, Alibaba.com, URL: http://www.alibaba.com/product-de tail/Magnesium-Powder-Price_1351745739.html

30. JB, 99.8\% Pure Magnesium Powder [WWW Document], 2014, Alibaba.com, URL: http://www.alibaba.com/prod uct-detail/99-8-Pure-Magnesium-Powder-Price_1786856 903.html? $\mathrm{s}=\mathrm{p}$

31. Tian Ma, Magnesium Powder Price [WWW Document], 2014, Alibaba.com, URL: http://www.alibaba.com/prod uct-detail/magnesium-powder-price_1725740532.html

32. KANGMENG, High Quality and Best Price Silicon Metal Powder Series $(98 \%, 98.6 \%, 99.5 \%, 99.9 \%$ ) [WWW Document], 2014, Alibaba.com, URL: http://www.alibaba.com/ product-detail/High-Quality-and-Best-Price-Sili con_1815532315.html

33. Star, Silicon Metal Raw Material Powder [WWW Document], 2014, Alibaba.com, URL: http://www.alibaba.com/ product-detail/Long-time-supply-silicon-metal-raw_1708 908489.html? $\mathrm{s}=\mathrm{p}$

34. TF, Price Powder Silicon Metal [WWW Document], 2014, Alibaba.com 
35. Refwin, Land Silicon Carbide [WWW Document], 2015, URL: http://www.refwin.com/news/news.asp?id=13038 (accessed on: 2015/01/01)

36. Silicon Carbide \& More, Silicon Carbide \& More [WWW Document], Kormac Kennedy, 2011, URL: http://www. siliconcarbideandmore.com/index_files/SiC39final.pdf (accessed on: 2015/01/01)

37. Stone Contact, S. Contact, Black Silicon Carbide for Abrasives [WWW Document], n.d., URL: http://www. stonecontact.com/products-135401/black-silicon-carbidefor-abrasives (accessed on: 2015/01/01)

38. AL, Top Grade BC Tin Metal Powder 300 Mesh 99.6\% [WWW Document], 2014, Alibaba.com, URL: http://www. alibaba.com/product-detail/Top-grade-BV-Tin-metal-pow der 1868219463.html

39. BAŌFULL, Tin Metal Powder 300 mesh 99.5\% [WWW Document], 2014, Alibaba.com, URL: http://www.alibaba. com/product-detail/Tin-metal-powder-300mesh-99-5_9250 62548.html

40. CDH857, China Tin Metal Powder [WWW Document], 2014, Alibaba.com, URL: http://www.alibaba.com/prod uct-detail/China-Tin-Metal-Powder 390493927.html?s=p

41. Longchen, ZINC CUT WIRE (SḦOT) 1.9mm [WWW Document], 2014, Alibaba.com, URL: http://www.alibaba. com/product-detail/ZINC-CUT-WIRE-SHOT-1-9mm_423 351754.html

42. Vantaa, Zinc Metal Powder [WWW Document], 2014, Alibaba.com, URL: http://www.alibaba.com/product-de tail/Hot-sale-zinc-metal-powder_1607519140.html

43. Zefeng, Factory Zinc Powder [WWW Document], 2014, Alibaba.com, URL: http://www.alibaba.com/product-detail/ Factory-Zinc-powder-Competitive-price_1309846248.html

44. Scott Metals, Scott Metals: Black Steel Pipe [WWW Document], n.d., URL: http://www.scottmetals.com.au/ pipe.php (accessed on: 2015/01/01)
45. All Things Stainless, Stainless Steel Sheet [WWW Document], n.d., URL: http://allthingsstainless.com.au/stain less-steel-sheet.html (accessed on: 2015/01/01)

46. Materialshandling.com, 205 Litre Stainless Steel Drums [WWW Document], n.d., URL: http://www.materialshan dling.com.au/products/205-litre-steel-drums/ (accessed on: 2015/01/01)

47. Australia Trade, A.T. Shipping, Container Sizes [WWW Document], n.d., URL: http://www.australiatrade.com. au/Shipping/ContainerSizeSales/ (accessed on: 2015/01/ 01)

48. Containerco, Containerco Shipping Container Sales \& Hire [WWW Document], n.d., URL: http://containerco.com.au/ shipping-container-sales-hire/ (accessed on: 2015/01/01)

49. anvilfire.com, Dempsey's Forge, Thermal Ceramics Kaowool [WWW Document], n.d., URL: http://www.anvilfire.com/ sales/pages/kaowool_index.htm (accessed on: 2015/01/01)

50. D. Kearney, B. Kelly, R. Cable, N. Potrovitza, P. Nava, U. Herrmann, J. Mahoney, R. Pacheco, H. Price, D. Blake, Assessment of a molten salt heat transfer fluid in a parabolic trough solar field, JSEE 125, 1 (2002)

51. J.K. Fink, L. Leibowitz, Thermodynamic and Transport Properties of Sodium Liquid and Vapor, 1995, doi:10.2172/94649

52. R. Jacob, N. Trout, R. Raud, S. Clarke, T.A. Steinberg, W. Saman, F. Bruno, Geopolymer encapsulation of a chloride salt phase change material for high temperature thermal energy storage, in SolarPACES 2015 (AIP Publishing, 2016), p. 50021, doi:10.1063/1.4949119

53. G.J. Janz, Molten Salts Handbook (Academic Press, 1967)

54. F. Bai, Y. Wang, Z. Wang, Y. Sun, A. Beath, Economic evaluation of shell-and-tube latent heat thermal energy storage for concentrating solar power applications, in SolarPACES 2014 (Elsevier, 2015)

Cite this article as: Alexander Post, Anthony Rawson, Heber Sugo, Dylan Cuskelly, Mark Copus, James Bradley, Erich Kisi, Price estimation for miscibility gap alloy thermal storage systems, Renew. Energy Environ. Sustain. 2, 32 (2017) 